\title{
Social facilitation of eating behavior in young opossums: I. Group vs. solitary feeding
}

\author{
JEROME J. PLATT ${ }^{1}$ AND W. T. JAMES \\ UNIVERSITY OF GEORGIA
}

A litter of eight young opossums was fed, under both group and solitary conditions, once a day for twenty days. Food intake under the group feeding condition significantly exceeded that under the individual feeding condition $(\mathrm{p}<.001)$. The amount of food taken in during each feeding session was found to increase more rapidly under the group feeding condition than under the individual feeding condition. The latter finding is of particular interest in the case of this mammal, which while living in a group while young, becomes increasingly more solitary in its living habits as it gets older.

It has been demonstrated that animals belonging to a wide variety of species will eat more when fed in a group than when fed individually. Among the species in which this has been demonstrated are fish, birds, rats, monkeys, and dogs (see James, 1960, for a complete list of these references). The current study is an investigation of the existence of this phenomenon in young opossums.

\section{Subjects}

Ss were a litter of 10 young opossums (Didelphis marsupialis virginiana), six male and four female. They had been removed from their mother's pouch at approximately 60 days of age, and bottle fed until they were old enough to eat by themselves. Ss had been removed from the pouch 25 days before the start of the experiment, and had been eating by themselves for approximately 16 days. Ss weighed an average of $84.0 \mathrm{gm}$ at the start of the experiment.

\section{Apparafus}

A large box, 30 in. $\times 30$ in. $\times 8$ in., covered with wire, was used for the group feeding condition of the experiment. Individual boxes, 12 in. $x 6$ in., also with wire roofs, were used for the individual feeding part of the experiment. Ss ate from a common white dish, large enough for all Ss to eat from at one time without difficulty, under the group feeding condition, and from smaller white dishes under the solitary feeding condition. Food for the Ss consisted of reconstituted condensed milk and canned horse meat, in equal parts, a highly preferred combination.

\section{Procedure}

Ss were removed daily from their common home cage and transported to the experimental room to be weighed before being placed into either the group or individual feeding boxes. Ss had available approximately twice their daily intake in food while in the experimental situation so that they would have a more than sufficient amount. Only indirect subdued lighting was available while in the experimental situation, as these animals were extremely photosensitive. Ss were allowed to remain in their feeding boxes for approximately 30-35 min. at each feeding so that they had an opportunity to return to the food dish more than once. Ss usually finished eating in approximately $10 \mathrm{~min}$., however, and retired to the corners of the box to groom themselves or to sleep, sometimes to explore the wire roof.

At the end of the experimental session Ss were reweighed and returned to their home cage. The paper lining of the feeding boxes were weighed with the animals before and after feeding so that any weight loss due to elimination would be accounted for. Upon being returned to their home cage, a pan of food was made available to the Ss. This food, and that received in the experimental sessions were the only sources of food the Ss had available. Observation indicated that the Ss would emerge to eat from the pan of food some $4-6 \mathrm{hr}$. or more after having been returned to the home cage. Ss did not drink water in the home cage. Instead, they preferred the milk which was available only in the experimental situation.

For sessions 1 to 10 , Ss were fed in the following order $(G=$ group feeding, $S=$ solitary feeding): SSGSSGGGSG. At this point in the experiment, two of the Ss, one male and one female, died from injuries received from fighting among themselves, and the experiment was discontinued for 12 days, during which time the animals were closely watched for evidence of more fighting. On the thirteenth day the experiment was renewed and Ss were fed in the following order for the next ten days: SGSGSGSGSG.

\section{Resulis}

Figure 1 graphically represents the average daily intake for the eight animals under the individual and social feeding conditions. The data were analyzed by means of a 2 by 2 by 5 repeated measures analysis of variance design. The two levels of the first factor were Condition I (individual feeding) and Condition II (group feeding). The two blocks of 10 trials rach were the second factor, and each of the five levels of factor three consisted of the daily food intakes of the eight anima.ls. Main effects significant beyond the .001 level were found for treatments, blocks of trials, and individual trials. Thus the mode of feeding produced a clear difference in intake over all trials, with more food intake under group as opposed to solitary feeding conditions. The significant $\mathrm{B}$ and $\mathrm{C}$ main effects demonstrate a generally increasing rate of food intake over blocks of trials, and trials, respectively, being most pronounced during the second block of trials (Fig. 1). 


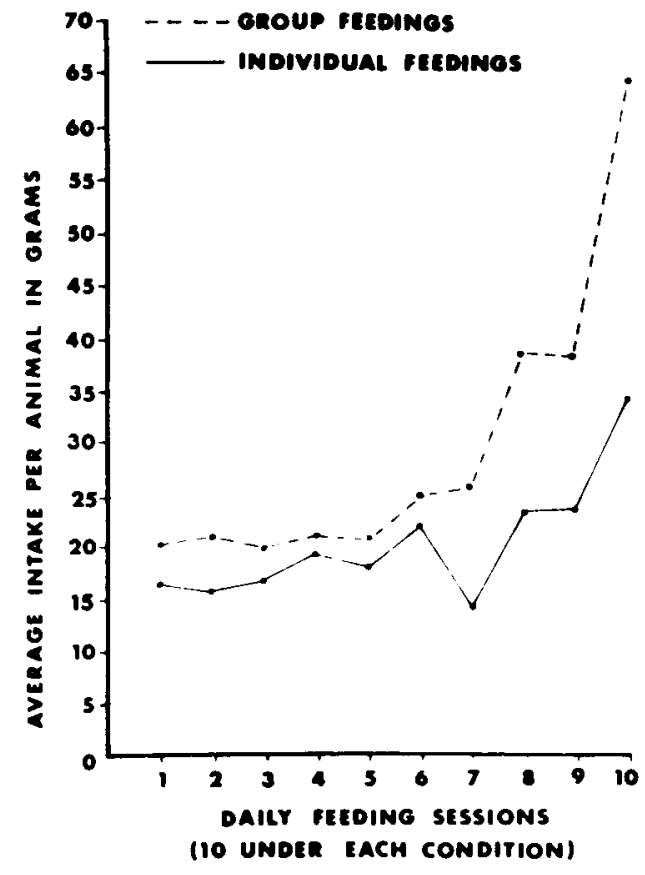

Fig. 1. Average food intake of the opossums under individual and social eating conditions.

The $\mathrm{AB}$ interaction (mode of feeding by blocks of trials) was significant at the .05 level, indicating that the rate of change in intake over trials differed significantly under the two conditions, with intake increasing more rapidly under the group feeding condition. Significant trials by blocks of trials and triple interaction effects were due to the non-parallelity of changes in intake over all trials and blocks of trials.

\section{Discussion}

The results of this study demonstrate that social facilitation of eating behavior is present in young opossums. Of particular interest is the fact that in the current study this effect became more pronounced over time, as evidenced by the progressive diversion in the intake curves in Fig. 1. The presence of such an effect in young dogs is also suggested by the data presented by James (1960). Whether this effect is due to the acquisition of more conditioned cues in the eating situation, which in turn lead to more socially facilitated eating, or to some other factor, cannot be said at the present time. This effect is, however, of particular interest in the case of the opossum, for while this animal lives together with its litter mates in close contact during the first few months of life, when the young do separate, they soon become so antagonistic to each other that if not kept apart there is serious risk of injury or death to each other, a risk that exists even when domesticated animals are brought together for mating (Crandall, 1964). Thus it is of more than passing interest that the social facilitation effect became more pronounced over time in this group of animals, especially since aggression within the group led to the deaths of two animals during the period the study was conducted. It may very well be that this socially facilitative effect exists in spite of natural aggressive tendencies on the part of these animals. Further research, utilizing both this group of Ss, and a separate group of wild adult opossums is currently in progress.

\section{References}

Crandall, L.S. Management of uild mammals in captivity. Chicago: University of Chicago, 1964.

James, W. T. The development of social facilitation of eating in puppies. J. genet. Psychol., 1960, 96, 123-127.

Note

1. National Aeronautics and Space Administration Pre-Doctoral Fellow. 